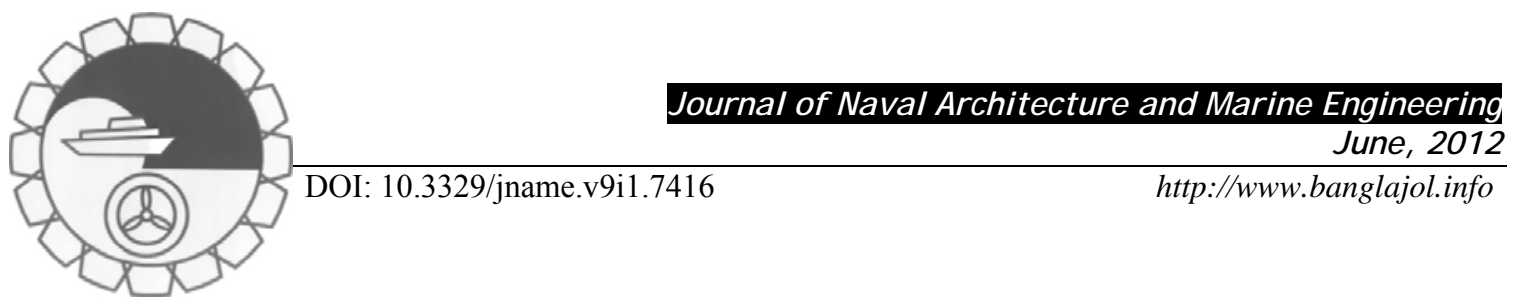

\title{
MELTING HEAT TRANSFER IN A NANOFLUID BOUNDARY LAYER ON A STRETCHING CIRCULAR CYLINDER
}

\author{
Rama Subba Reddy Gorla $^{1}$, Ali Chamkha ${ }^{2 *}$ and Eisa Al-Meshaiei ${ }^{2}$ \\ ${ }^{1}$ Department of Mechanical Engineering, Cleveland State University, Cleveland, Ohio, USA. Email: r.gorla@esuohio.edu \\ ${ }^{2}$ Public Authority for Applied Education and Training, Shuweikh, Kuwait. *Email: achamkha@yahoo.com
}

\begin{abstract}
:
A boundary layer analysis is presented for the warm, laminar nanoliquidfluid flow to a melting cylindrical surface moving parallel to a unform stream. The resulting system of non-linear ordinary differential equations is solved numerically using Runge-Kutta method with shooting techniques. Numerical results are obtained for the velocity, temperature and concentration distributions, as well as the friction factor, local Nusselt number and local Sherwood number for several values of the parameters, namely, the Reynolds number, Prandtl number and nanofluid parameters. The obtained results are presented graphically and in tabular form and the physical aspects of the problem are discussed.
\end{abstract}

Keywords: Stretching cylinder, melting heat transfer, nanofluid etc.

\section{NOMENCLATURE}

$\mathrm{C}$

$\mathrm{D}_{\mathrm{B}}$

$\mathrm{D}_{\mathrm{T}}$

g

$\mathrm{k}_{\mathrm{m}}$

$\mathrm{K}$

Le

M

$\mathrm{n}$

$\mathrm{N}_{\mathrm{b}}$

$\mathrm{N}_{\mathrm{t}}$

$\mathrm{Nu}$

$\mathrm{p}$

q

$\operatorname{Re}$

$\mathrm{T}$

$\mathrm{T}_{\mathrm{m}}$

$\mathrm{T}_{0}$ specific heat

Brownian diffusion coefficient

thermophoretic diffusion

coefficient

reduced stream function

gravitational acceleration

effective thermal conductivity

permeability of porous medium

Lewis number

melting parameter

concentration

Brownian motion parameters

thermophoresis parameters

Nusselt number

pressure

wall heat flux

Reynolds number

temperature

melting surface temperature

solid surface temperature
$\mathrm{T}_{\infty} \quad$ ambient temperature

u, w Darcy velocity components

$(\mathrm{r}, \mathrm{z})$

Cartesian coordinates

Greek Symbols:

$\alpha_{\mathrm{m}} \quad$ thermal diffusivity

$\eta \quad$ dimensionless distance

$\theta$ dimensionless temperature

$\emptyset \quad$ dimensionless concentration

$\mu \quad$ viscosity of fluid

$\rho_{\mathrm{f}} \quad$ fluid density

$\rho_{\mathrm{p}} \quad$ nano-particle mass density

$(\rho \mathrm{C})_{\mathrm{f}} \quad$ heat capacity of the fluid

$(\rho C)_{\mathrm{m}} \quad$ effective heat capacity

$(\rho C)_{p} \quad$ effective heat capacity of nano-

particle material

$\tau \quad$ heat capacity ratio

Subscripts

W Refers to condition at wall

$\infty \quad$ Refers to condition far from the wal 


\section{Introduction}

The study of convective heat transfer in nanofluids is gaining a lot of attention. The nanofluids have many applications in the industries since materials of nanometer size have unique physical and chemical properties. Nanofluids are solid-liquid composite materials consisting of solid nanoparticles or nanofibers with sizes typically of 1-100 nm suspended in liquid. Nanofluids have attracted great interest recently because of reports of greatly enhanced thermal properties. For example, a small amount $(<1 \%$ volume fraction) of $\mathrm{Cu}$ nanoparticles or carbon nanotubes dispersed in ethylene glycol or oil is reported to increase the inherently poor thermal conductivity of the liquid by $40 \%$ and $150 \%$ respectively (Eastman et al, 2001, Choi et al, 2001). Conventional particle-liquid suspensions require high concentration $(>10 \%)$ of particles to achieve such enhancement. However, problems of rheology and stability are amplified at high concentration, precluding the widespread use of conventional slurries as heat transfer fluids. In some cases, the observed enhancement in thermal conductivity of nanofluids is orders of magnitude larger than predicted by well-established theories. Other perplexing results in this rapidly evolving field include a surprisingly strong temperature dependence of the thermal conductivity (Patel et al, 2003) and a three-fold higher critical heat flux compared with the base fluids (You et al, 2003, Sakiadis, 1961). These enhanced thermal properties are not merely of academic interest. If confirmed and found consistent, they would make nanofluids promising for application in thermal management. Furthermore, suspensions of metal nanoparticles are also being developed for other purposes, such as medical applications including cancer therapy. The interdisciplinary nature of nanofluid research presents a great opportunity for exploration and discovery at the frontiers of nanotechnology.

The characteristics of flow and heat transfer of a viscous and incompressible fluid over flexed or continuously moving flat surfaces in a moving or a quiescent fluid are well understood. These flows occur in many manufacturing processes in modern industry, such as hot rolling, hot extrusion, wire drawing and continuous casting. For example, in many metallurgical processes such as drawing of continuous filaments through quiescent fluids and annealing and tinning of copper wires, the properties of the end product depends greatly on the rare of cooling involved in these processes. Sakiadis (1961) was the first one to analyze the boundary layer flow on continuous surfaces. Crane (1970) obtained an exact solution the boundary layer flow of Newtonian fluid caused by the stretching of an elastic sheet moving in its own plane linearly. Tsou et al. (1967) extended the research to the heat transfer phenomenon of the boundary layer flow on a continuous moving surface.Gorla and Sidawi (1994) studied the characteristics of flow and heat transfer from a continuous surface with suction and blowing. Wang (1988) analyzed the flow due to a stretching circular cylinder in a stagnant ambient viscous, incompressible, Newtonian fluid. Chamkha et. al. (2010) studied the heat transfer to the stretching cylinder moving in a stagnant incompressible, Newtonian fluid. Ishak (2010) presented a similarity solution for the flow and heat transfer to a permeable surface with convective boundary conditions. Ishat et al. (2008) considered surface mass transfer effects on heat transfer from a stretching cylinder.

Phase change heat transfer finds applications in magma solidification, permafrost melting, preparation of semiconductor materials etc. The analogy between melting and diffusion mass transfer or transpiration cooling was noted by Huang and Shih (1975). Pedroso and Domoto (1973) developed a method for calculating melting rates based on the diffusion/melting analogy. Epstein (1975) considered the effect of melting on heat transfer to submerged bodies. Epstein and Cho (1976) analyzed melting heat transfer from a flat plate. Ishak et al. (2010) considered melting heat transfer from a moving flat plate. Bachok et al. (2010) investigated melting heat transfer at a stagnation point on a stretching sheet.

We present here a similarity analysis for the problem of steady boundary-layer flow and heat transfer from a warm, laminar liquid flow to a melting cylinder moving parallel to a constant free stream of a nanofluid. It is assumed that the melting of the plate takes place at a steady state. The development of the velocity, temperature and concentration distributions have been illustrated for several values of nanofluid parameters, Lewis number and melting parameter.

\section{Analysis}

Consider a stretching circular tube of radius a moving at a velocity $\mathrm{w}=2 \mathrm{cz}$ in a stagnant free stream nanofluid. The physical properties of the fluid are assumed to be constant. Under such condition, the governing equations of the steady, laminar boundary-layer flow on the moving surface are given by: 
$\frac{\partial(r w)}{\partial z}+\frac{\partial(r u)}{\partial r}=0$

$w \frac{\partial w}{\partial z}+u \frac{\partial w}{\partial r}=v\left(\frac{\partial^{2} w}{\partial r^{2}}+\frac{1}{r} \frac{\partial w}{\partial r}\right)$

$w \frac{\partial u}{\partial z}+u \frac{\partial u}{\partial r}=-\frac{1}{\rho_{\mathrm{f}}} \frac{\partial p}{\partial r}+v\left(\frac{\partial^{2} u}{\partial r^{2}}+\frac{1}{r} \frac{\partial u}{\partial r}-\frac{u}{r^{2}}\right)$

$w \frac{\partial T}{\partial z}+u \frac{\partial T}{\partial r}=\frac{\alpha}{r} \frac{\partial}{\partial r}\left(r \frac{\partial T}{\partial r}\right)+\tau\left\{\mathrm{D}_{\mathrm{B}}\left(\frac{\partial \mathrm{n}}{\partial \mathrm{z}} \frac{\partial \mathrm{T}}{\partial \mathrm{z}}+\frac{\partial \mathrm{n}}{\partial \mathrm{r}} \frac{\partial \mathrm{T}}{\partial \mathrm{r}}\right)+\left(\frac{\mathrm{D}_{\mathrm{T}}}{\mathrm{T}_{\infty}}\right)\left[\left(\frac{\partial \mathrm{T}}{\partial \mathrm{z}}\right)^{2}+\left(\frac{\partial \mathrm{T}}{\partial \mathrm{r}}\right)^{2}\right]\right\}$

$w \frac{\partial n}{\partial z}+u \frac{\partial n}{\partial r}=\frac{D_{B}}{r} \frac{\partial}{\partial r}\left(r \frac{\partial n}{\partial r}\right)+\left(\frac{\mathrm{D}_{\mathrm{T}}}{\mathrm{T}_{\infty}}\right) \frac{1}{r} \frac{\partial}{\partial r}\left(r \frac{\partial T}{\partial r}\right)$

The boundary conditions are given by,

$r=\mathrm{a}: u=0, \mathrm{w}=2 \mathrm{cz}, k \frac{\partial T}{\partial y}=\rho\left[\lambda+C_{s}\left(T_{m}-T_{0}\right)\right] v_{w}, \mathrm{n}=\mathrm{n}_{\mathrm{w}}$

$r \rightarrow \infty: w=0, T=T_{\infty}, n=n_{\infty}$

The boundary layer flows in nano fluids have been analyzed recently by Nield and Kuznetsov (2009.a) and Nield and Kuznetsov (2009.b). Our model used for nanofluid is similar to these authors.

Proceeding with the analysis, we define the following transformations:

$\eta=\left(\frac{r}{a}\right)^{2}$

$\mathrm{u}=-\mathrm{c} \mathrm{a}\left(\frac{f(\eta)}{\sqrt{\eta}}\right)$

$\mathrm{W}=2 \mathrm{c} \mathrm{z} f^{\prime}(\eta)$

$\theta=\frac{T-T_{\infty}}{T_{w}-T_{\infty}}$

$\phi=\frac{\stackrel{n}{n-n_{\infty}}}{n_{w}-n_{\infty}}$

Using the transformation variables defined in Equation (7), the governing transformed equations may be written as:

$\eta \mathrm{f}^{\prime \prime}+\mathrm{f} "+\operatorname{Re}_{a}\left(\mathrm{ff}^{\prime \prime}-\mathrm{f}^{\prime 2}\right)=0$

$\frac{\theta \prime \prime}{\mathrm{Pr}_{\mathrm{r}}}+\frac{\theta \prime}{\mathrm{Pr}_{\mathrm{r}}}+\mathrm{N}_{\mathrm{b}} \theta^{\prime} \phi^{\prime}+\mathrm{N}_{\mathrm{t}}\left(\theta^{\prime}\right)^{2}+\frac{\mathrm{Re}_{\mathrm{a}}}{2 \eta} \mathrm{f} \theta^{\prime}=0$

$\phi^{\prime \prime}+\phi^{\prime}\left(\frac{1}{2} \mathrm{~L}_{\mathrm{e}} \operatorname{Re}_{\mathrm{a}} \mathrm{f}+\frac{1}{\eta}\right)+\frac{\mathrm{N}_{\mathrm{t}}}{\mathrm{N}_{\mathrm{b}}} \frac{1}{\eta} \theta^{\prime}+\frac{\mathrm{N}_{\mathrm{t}}}{\mathrm{N}_{\mathrm{b}}} \theta^{\prime \prime}=0$

The transformed boundary conditions are given by

$\eta=1: \operatorname{Pr} \cdot R e_{a} \cdot f+2 M \theta^{\prime}=0, \mathrm{f}=0, \mathrm{f}^{\prime}=1, \theta=1, \phi=1$

$\eta \rightarrow \infty: \mathrm{f}^{\prime}=0, \theta=0, \phi=0$

where prime denote differentiation with respect to $\eta$ and the four parameters are defined by

$M=\frac{C_{f}\left(T_{\infty}-T_{m}\right)}{\lambda+C_{S}\left(T_{m}-T_{0}\right)}$

$\mathrm{N}_{\mathrm{t}}=\frac{\varepsilon(\rho \mathrm{C}) \mathrm{p} \mathrm{D}_{\mathrm{T}}\left(\mathrm{T}_{\mathrm{w}}-\mathrm{T}_{\infty}\right)}{(\rho \mathrm{C})_{\mathrm{f}} \mathrm{T}_{\infty} \alpha_{\mathrm{m}}}$

$\mathrm{N}_{\mathrm{b}}=\frac{\varepsilon(\rho \mathrm{C}) \mathrm{p}_{\mathrm{B}}\left(\mathrm{T}_{\mathrm{w}}-\mathrm{T}_{\infty}\right)}{(\rho \mathrm{C})_{\mathrm{f}} \alpha_{\mathrm{m}}} ; \mathrm{Re}=\frac{\mathrm{c} \mathrm{a}^{2}}{2 v} ; \mathrm{L}_{\mathrm{e}}=\frac{v}{\mathrm{D}_{\mathrm{B}}} ; \mathrm{P}_{\mathrm{r}}=\frac{v}{\alpha}$

$\tau=\frac{\varepsilon(\rho \mathrm{C})_{\mathrm{p}}}{(\rho \mathrm{C})_{\mathrm{f}}}$

Here, $\operatorname{Pr}, L e, N_{b}$ and $N_{t}$ denote the Prandtl number, the Lewis number, the Brownian motion parameter and the thermophoresis parameter, respectively. It is important to note that this boundary value problem reduces to the classical problem of flow and heat and mass transfer due to a stretching cylinder in a viscous fluid when $\mathrm{Nb}$ and Nt are zero.

The quantities of practical interest, in this study, are the friction factor $\mathrm{C}_{\mathrm{f}}$, Nusselt number $\mathrm{Nu}$ and the Sherwood number $S h$ which are defined as:

Melting heat transfer in a nanofluid boundary layer on a stretching circular cylinder... 
The wall shear stress is given by

$\left.\tau_{\mathrm{w}}=\mu \frac{\partial \mathrm{w}}{\partial \mathrm{r}}\right)_{\mathrm{r}=\mathrm{a}}=\frac{4 \mu \mathrm{cz}}{\mathrm{a}} \mu f^{\prime \prime}(1)$

The friction factor $\mathrm{C}_{\mathrm{f}}$ is give by

$\mathrm{C}_{\mathrm{f}}=\frac{\tau_{\mathrm{w}}}{\frac{\rho W^{2}}{2}}=4 \frac{z}{a} \frac{1}{R e_{\mathrm{z}}} \mathrm{f}^{\prime \prime}(1)$

where $\operatorname{Re}_{\mathrm{z}}=\frac{c z^{2}}{2 v}$

The local heat transfer rate (Local Nusselt number) is given by

$N u_{x}=\frac{q_{w} x}{k\left(T_{w}-T_{\infty}\right)}=-2 \sqrt{\frac{R e_{z}}{R e_{a}}} \theta^{\prime}(1)$

Similarly the local Sherwood number is given by

$S h_{x}=\frac{q_{m} x}{D_{B}\left(n_{w}-n_{\infty}\right)}=-2 \sqrt{\frac{R e_{z}}{R e_{a}}} \phi^{\prime}(1)$

where $\mathrm{q}_{\mathrm{w}}$ and $\mathrm{q}_{\mathrm{m}}$ are wall heat and mass flux rates, respectively.

\section{Results and Discussion}

The nonlinear ordinary differential equations (8)-(10), satisfying the boundary conditions (11) were integrated numerically by using the fourth-order Runge-Kutta scheme along with the shooting method for several values of the governing parameters, namely, melting parameter M, Prandtl number (Pr), Lewis number (Le), Brownian motion parameter $\left(\mathrm{N}_{\mathrm{b}}\right)$ and thermophoresis parameter $\left(\mathrm{N}_{\mathrm{t}}\right)$. As per Pantokratoras (2009), the value of the edge of the boundary layer distance $\eta_{\infty}$ was set to be 35 . This was found to give accurate results. In order to assess the accuracy of the present results, we obtained results for the reduced friction factor - $f^{\prime \prime}(1)$ and Nusselt number $-\theta^{\prime}(1)$ by ignoring the effects of $\mathrm{M}, \mathrm{N}_{\mathrm{b}}$ and $\mathrm{N}_{\mathrm{t}}$. These results are shown in Tables 1-3. A comparison of our results with literature values indicates excellent agreement and therefore our results are highly accurate.

Table 1: Comparison of results for $-\mathrm{f}^{\prime \prime}(1)$

\begin{tabular}{lllll}
\hline $\mathrm{Re}_{\mathrm{a}}$ & Present results & Wang (1988) & Chamkha et al (2010) & Ishak et al (2008) \\
\hline 0.5 & 0.88700 & 0.88220 & 0.88700 & 0.8827 \\
1.0 & 1.17923 & 1.17776 & 1.17953 & 1.1781 \\
2.0 & 1.59448 & 1.59390 & 1.59444 & 1.5941 \\
5.0 & 2.41755 & 2.41745 & 2.41798 & 2.4175 \\
10.0 & 3.34467 & - & - & 3.3445
\end{tabular}

Table 2: Comparison of results for $-\theta^{\prime}(1)\left(\mathrm{N}_{\mathrm{t}}=\mathrm{N}_{\mathrm{b}}=0, \mathrm{Re}_{\mathrm{a}}=3\right)$

\begin{tabular}{ccc}
\hline $\operatorname{Pr}$ & Present results & Chamkha et al (2008) \\
\hline 0.70 & 1.15053 & 1.15053 \\
2.00 & 2.10654 & 2.10655 \\
7.00 & 4.23743 & 4.23743
\end{tabular}

Table 3: Comparison of results for $-\theta^{\prime}(1)\left(\mathrm{N}_{\mathrm{t}}=\mathrm{N}_{\mathrm{b}}=0, \mathrm{Re}_{\mathrm{a}}=10\right)$

\begin{tabular}{ccc}
\hline $\operatorname{Pr}$ & Present results & Ishak et al (2008) \\
\hline 0.70 & 1.15683 & 1.15683 \\
2.00 & 3.03604 & 3.0360 \\
7.00 & 6.15919 & 6.1592 \\
10.00 & 7.46678 & 7.4668 \\
\hline
\end{tabular}

Melting heat transfer in a nanofluid boundary layer on a stretching circular cylinder... 
Rama Subba Reddy Gorla , Ali Chamkha, Eisa Al-Meshaiei / Journal of Naval Architecture and Marine Engineering 9(2012) 1-10

Table 4: Effects of $\mathrm{M}$ on $-\mathrm{f}^{\prime \prime}(1),-\theta^{\prime}(1)$ and $-\phi^{\prime}(1)$ for $\mathrm{N}_{\mathrm{b}}=0.3, \mathrm{~N}_{\mathrm{t}}=0.1, \mathrm{Le}=10, \operatorname{Pr}=0.007$ and $\mathrm{Re}=5.0$

\begin{tabular}{|c|c|c|c|}
\hline M & $-f^{\prime \prime}(1)$ & $-\theta^{\prime}(1)$ & $-\phi^{\prime}(1)$ \\
\hline 0 & 1.465554 & $2.885982 \mathrm{E}-01$ & 4.332448 \\
\hline 0.5 & 1.225042 & $2.894680 \mathrm{E}-01$ & 6.351898 \\
\hline 1.0 & 1.079356 & $2.913474 \mathrm{E}-01$ & 8.526056 \\
\hline 2.0 & $9.033523 \mathrm{E}-01$ & $2.939987 \mathrm{E}-01$ & 13.126320 \\
\hline 3.0 & $7.967334 \mathrm{E}-01$ & $2.962927 \mathrm{E}-01$ & 17.872870 \\
\hline 5.0 & $6.672747 \mathrm{E}-01$ & $3.004993 \mathrm{E}-01$ & 27.423650 \\
\hline
\end{tabular}

Table 5: Effects of Re on -f"(1), $-\theta^{\prime}(0)$ and $-\phi^{\prime}(0)$ for $M=1.0, N_{b}=0.3, N_{t}=0.1, L e=10$ and $\operatorname{Pr}=1.0$

\begin{tabular}{|c|c|c|c|}
\hline Re & $-f^{\prime \prime}(1)$ & $-\theta^{\prime}(1)$ & $-\phi^{\prime}(1)$ \\
\hline 0.5 & $8.856947 \mathrm{E}-01$ & $3.130347 \mathrm{E}-01$ & 1.664970 \\
\hline 1.0 & 1.179914 & $3.768276 \mathrm{E}-01$ & 2.143076 \\
\hline 2.0 & 1.595489 & $4.730244 \mathrm{E}-01$ & 2.808954 \\
\hline 5.0 & 2.418254 & $6.765498 \mathrm{E}-01$ & 4.110941 \\
\hline 10 & 3.346068 & & 5.565769 \\
\hline
\end{tabular}

Table 6: Effects of Le on $-\mathrm{f}^{\prime \prime}(1),-\theta^{\prime}(1)$ and $-\phi^{\prime}(1)$ for $\mathrm{M}=1.0, \mathrm{~N}_{\mathrm{b}}=0.3, \mathrm{~N}_{\mathrm{t}}=0.1, \operatorname{Pr}=1.0$ and $\mathrm{Re}=5.0$

\begin{tabular}{|c|c|c|c|}
\hline Le & $-f^{\prime \prime}(1)$ & $-\theta^{\prime}(1)$ & $-\phi^{\prime}(1)$ \\
\hline 1 & 2.418453 & $7.238915 \mathrm{E}-01$ & 1.320297 \\
\hline 10 & 2.418254 & $6.765498 \mathrm{E}-01$ & 4.110941 \\
\hline $10^{2}$ & 2.418129 & $6.578494 \mathrm{E}-01$ & 12.78660 \\
\hline $10^{3}$ & 2.418007 & $6.524682 \mathrm{E}-01$ & 40.21021 \\
\hline
\end{tabular}


Table 7: Effects of $\mathrm{N}_{t}$ on $-\mathrm{f}^{\prime \prime}(1),-\theta^{\prime}(1)$ and $-\phi^{\prime}(1)$ for $\mathrm{M}=0.5, \mathrm{~N}_{\mathrm{b}}=0.3, \mathrm{Le}=10, \operatorname{Pr}=1.0$ and $\mathrm{Re}=5.0$

\begin{tabular}{|c|c|c|c|}
\hline $\mathrm{N}_{\mathrm{t}}$ & $-\mathrm{f}^{\prime \prime}(1)$ & $-\theta^{\prime}(1)$ & $\left.-\phi^{\prime} 1\right)$ \\
\hline 0.1 & 1.465142 & $9.067177 \mathrm{E}-01$ & 4.340492 \\
\hline 0.2 & 1.465078 & $8.648823 \mathrm{E}-01$ & 4.359981 \\
\hline 0.3 & 1.465281 & $8.250847 \mathrm{E}-01$ & 4.389859 \\
\hline 0.4 & 1.465446 & $7.873235 \mathrm{E}-01$ & 4.428391 \\
\hline 0.5 & 1.465281 & $7.520800 \mathrm{E}-01$ & 4.474232 \\
\hline
\end{tabular}

Table 8: Effects of $\mathrm{N}_{\mathrm{b}}$ on $-\mathrm{f}^{\prime \prime}(1),-\theta^{\prime}(1)$ and $-\phi^{\prime}(1)$ for $\mathrm{M}=0.5, \mathrm{~N}_{\mathrm{t}}=0.3, \mathrm{Le}=10, \operatorname{Pr}=1.0$ and $\mathrm{Re}=5.0$

\begin{tabular}{|c|c|c|c|}
\hline $\mathrm{N}_{\mathrm{b}}$ & $-\mathrm{f}^{\prime \prime}(1)$ & $-\theta^{\prime}(1)$ & $-\phi^{\prime}(1)$ \\
\hline 0.1 & 1.465203 & $9.769198 \mathrm{E}-01$ & 4.191690 \\
\hline 0.2 & 1.465203 & $8.978819 \mathrm{E}-01$ & 4.344063 \\
\hline 0.3 & 1.465281 & $8.250847 \mathrm{E}-01$ & 4.389859 \\
\hline 0.4 & 1.465399 & $7.565706 \mathrm{E}-01$ & 4.410043 \\
\hline 0.5 & 1.465446 & $6.942467 \mathrm{E}-01$ & 4.419178 \\
\hline
\end{tabular}

Tables 4-8 display the resulting values of velocity gradient $-f^{\prime \prime}(1)$, the surface heat transfer rate $-\theta^{\prime}(1)$ and the mass transfer rate $-\phi^{\prime}(1)$, which are proportional to the friction factor, Nusselt number and Sherwood number respectively. The results in Table 3 indicate that effect of increasing the melting parameter $\mathrm{M}$ is to increase the heat and mass transfer rates from the surface and decrease the friction factor. Table 4 indicates that as $\mathrm{Re}$ increases, friction factor as well as the heat and mass transfer rates increase. Table 5 indicates that as the Lewis number, Le increases, mass transfer rates get augmented. Tables 6 and 7 indicate that as $\mathrm{N}_{t}$ and $\mathrm{N}_{\mathrm{b}}$ increase, heat transfer rates decrease whereas the mass transfer rates increase.

Figures 1-3 display results for the variation of velocity, temperature and concentration within the boundary layer. As $\mathrm{M}$ increases, the velocity within the boundary layer increases and the concentration decreases. The concentration boundary layer thickness decreases as $\mathrm{M}$ increases. This enhances the mass transfer rates.

Figures 4-6 and show the velocity, temperature and concentration distributions within the boundary layer as the Reynolds number, Re increases. The velocity, temperature and concentration within the boundary layer decrease as Re increases. 


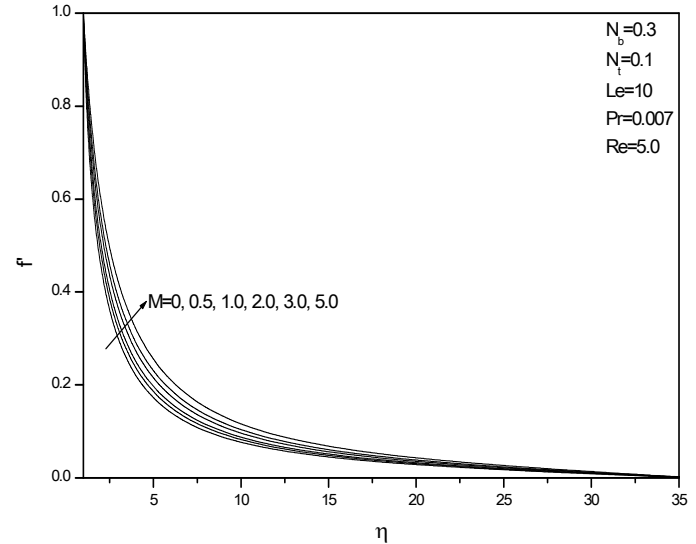

Fig. 1: Effects of $\mathrm{M}$ on velocity profiles

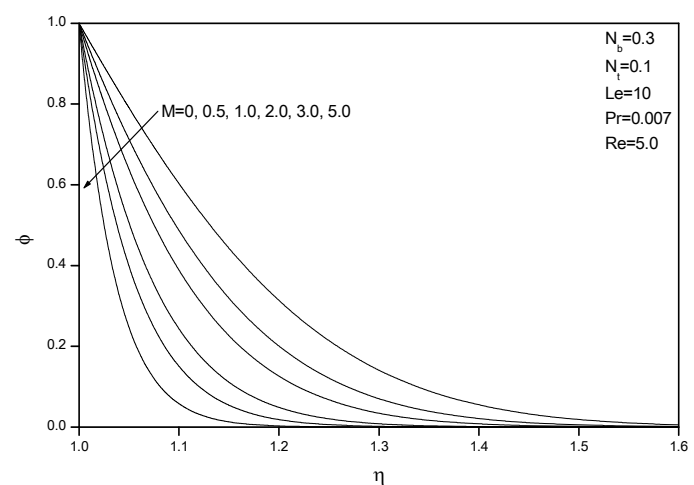

Fig.3: Effects of $\mathrm{M}$ on solid volume fraction profiles

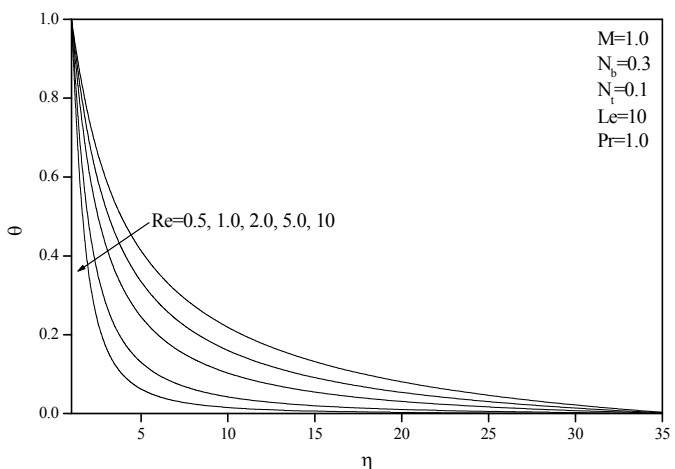

Fig. 5: Effects of Re on temperature profiles

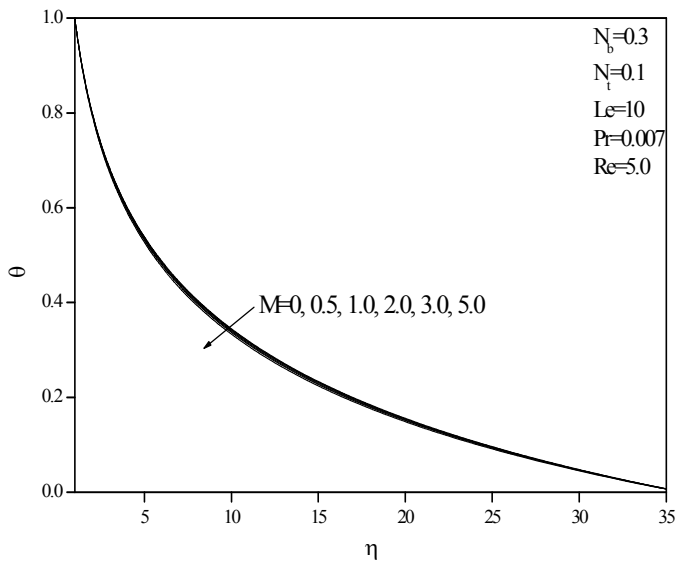

Fig. 2: Effects of $\mathrm{M}$ on temperature profiles

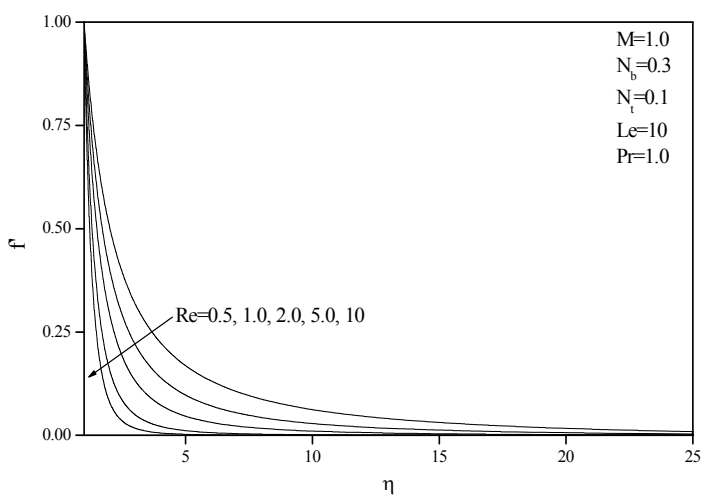

Fig. 4: Effects of Re on velocity profiles

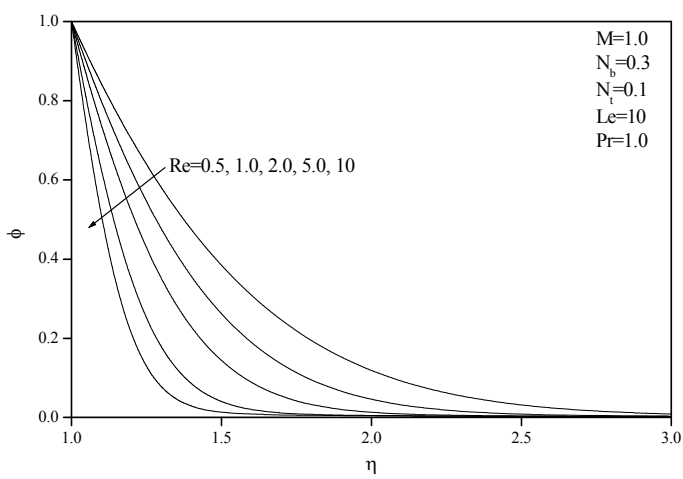

Fig. 6: Effects of Re on solid volume fraction profiles 


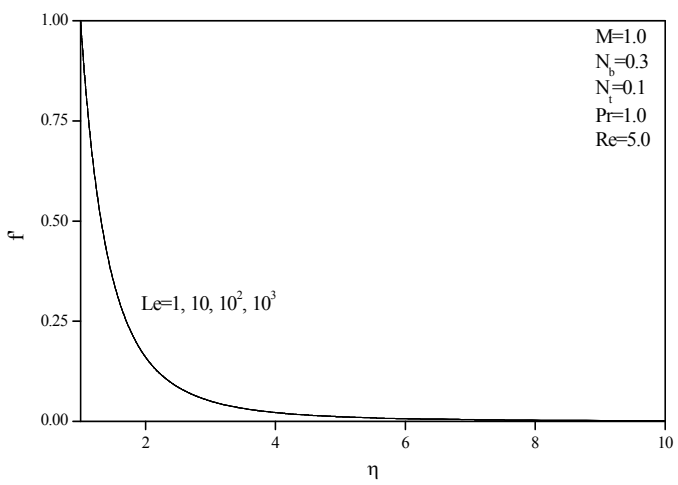

Fig. 7: Effects of Le on velocity profiles

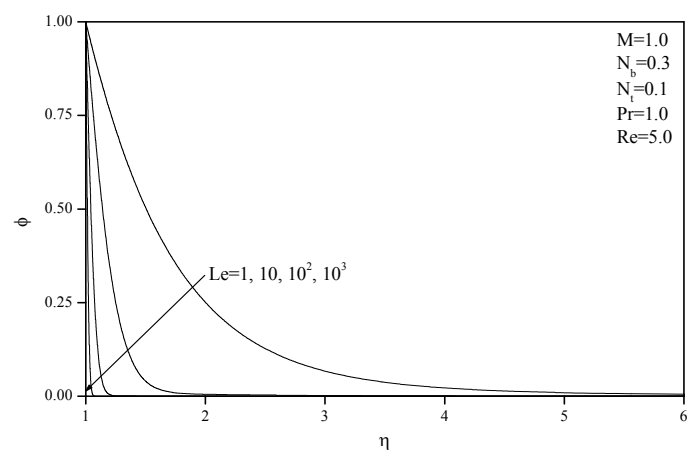

Fig. 9: Effects of Le on solid volume fraction profiles

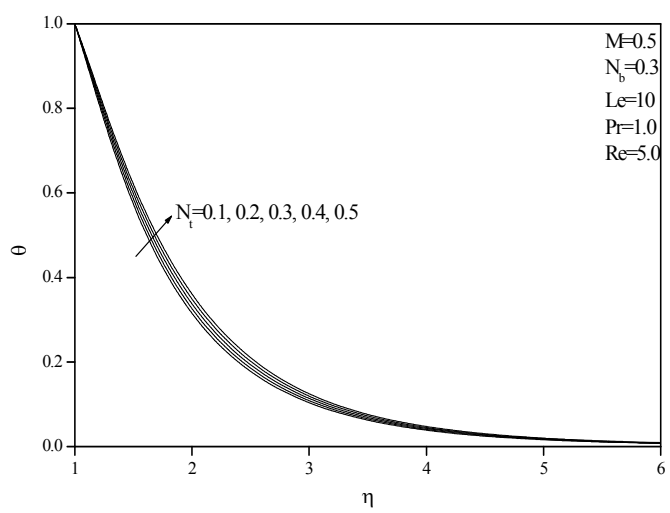

Fig. 11: Effects of $\mathrm{N}_{\mathrm{t}}$ on temperature profiles

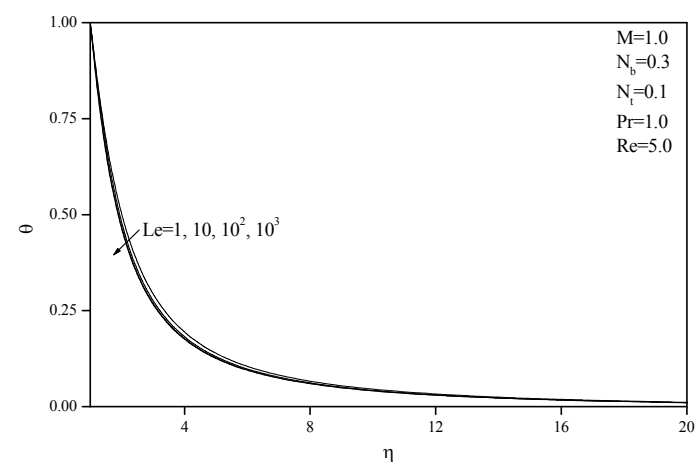

Fig. 8: Effects of Le on temperature profiles

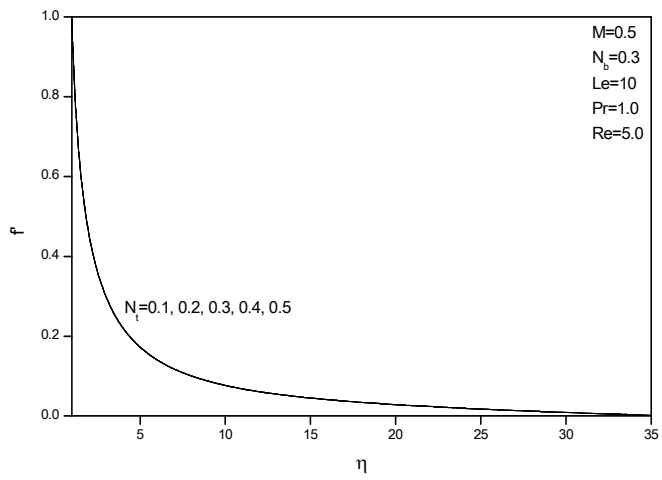

Fig. 10: Effects of $\mathrm{N}_{\mathrm{t}}$ on velocity profiles

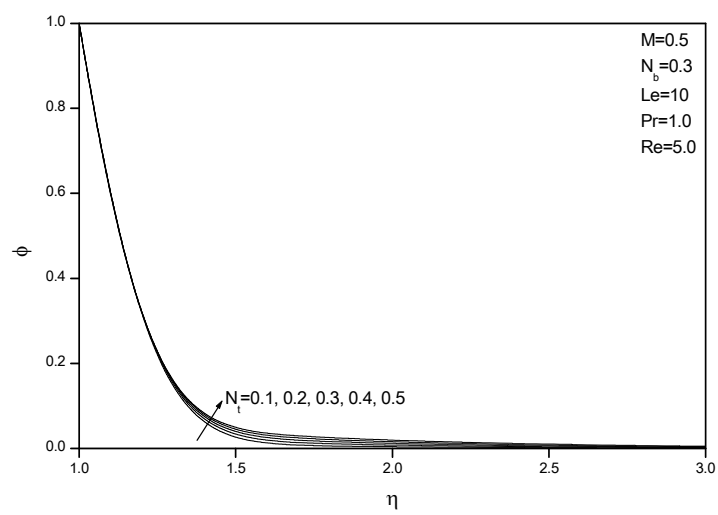

Fig. 12: Effects of $\mathrm{N}_{\mathrm{t}}$ on solid volume fraction profiles

Figures 7 and 8 indicate that Le has no significant effect on the velocity and temperature distributions. Figure 9 shows the concentration distribution as the Lewis number increases. As Le increases, we observe that the concentration decreases and the concentration boundary layer thickness decreases. This in turn increases the 
surface mass transfer rates as Le increases. From Figures 10-15, we observe that as $\mathrm{N}_{\mathrm{t}}$ increases, the temperature and concentration increase. As $\mathrm{N}_{\mathrm{b}}$ increases, the temperature increases whereas the concentration decreases. The thickness of the boundary layer for concentration is smaller than the thermal boundary layer thickness.

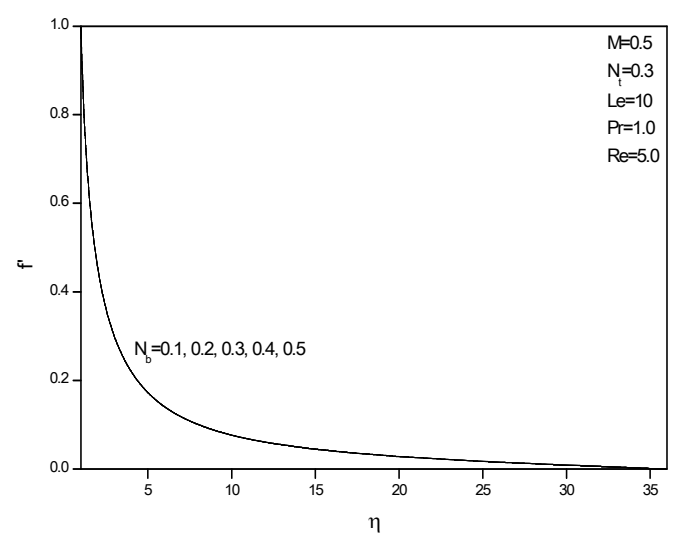

Fig. 13: Effects of $\mathrm{N}_{\mathrm{b}}$ on velocity profiles

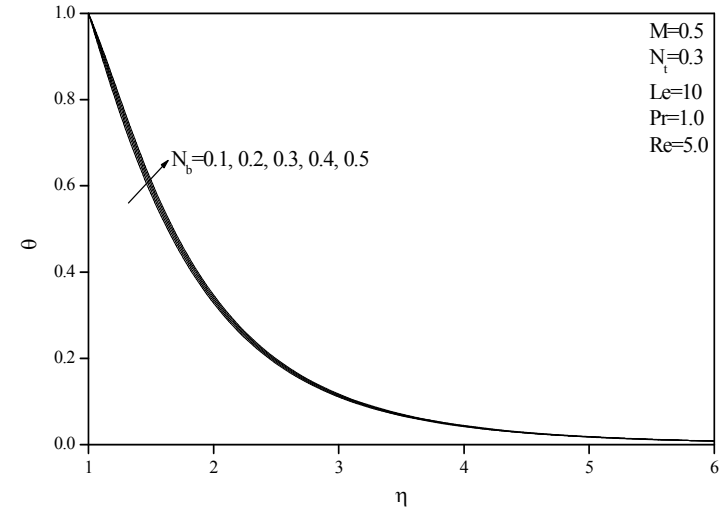

Fig. 14: Effects of $\mathrm{N}_{\mathrm{b}}$ on temperature profiles

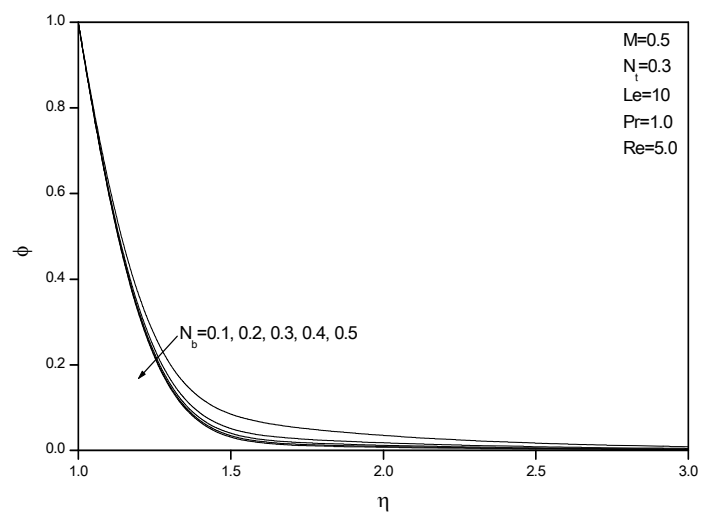

Fig. 15: Effects of $\mathrm{N}_{\mathrm{b}}$ on solid volume fraction profiles

\section{Concluding Remarks}

In this work, we have studied the problem of the steady boundary layer flow of a warm, laminar nanoliquid over a melting cylinder moving parallel to a uniform free stream of the same material. The governing boundary layer equations are solved numerically using the fourth-order Runge-Kutta scheme along with the shooting method. The development of the Nusselt number and Sherwood number as well as the temperature, concentration and velocity distributions for various values of the velocity ratio, melting and nanofluid parameters has been discussed and illustrated in tabular forms and graphs. The results indicate that the melting phenomenon increases the heat transfer rate, (Nusselt number) at the solid/fluid interface. The nanofluid parameters display a considerable effect on the rates of heat transfer and mass transfer. 


\section{References}

Bachok, N., Ishak, A. and Pop, I. (2010): Melting Heat Transfer in Boundary Layer Stagnation-point Flow towards a Stretching/Shrinking Sheet, Physics Letters A, Vol. 374, 2010, pp. 4075-4079. http://dx.doi.org/10.1016/j.physleta.2010.08.032

Chamkha, A. J., Abd El-Aziz, M. M. and Ahmed, S. E. (2010): Effects of Thermal Stratification on Flow and Heat Transfer Due to a Stretching Cylinder with Uniform Suction/Injection, Int. J. Energy \& Technology, Vol. 2, pp. 1-7.

Choi, S. U. S., Zhang, Z. G., Yu, W., Lockwood, F. E., and Grulke, E.A. (2001): Anomalous Thermal Conductivity Enhancement On Nanotube Suspension, Applied Physics Letters, Vol. 79, pp.2252-2254. http://dx.doi.org/10.1063/1.1408272

Crane, L. J. (1970): Flow Past a Stretching Plate, ZAMP, Vol. 21, pp. 645-647. http://dx.doi.org/10.1007/BF01587695

Eastman, J. A., Choi, S. U. S., Li, S., Yu, W. and Thompson, L. J. (2001): Anomalously Increased Effective Thermal Conductivities Containing Copper Nanoparticles, Applied Physics Letters, Vol. 78, pp. 718-720. http://dx.doi.org/10.1063/1.1341218

Epstein, M. (1975): The Effect of Melting on Heat Transfer to Submerged Bodies, Letters in Heat and Mass Transfer, Vol. 2, pp. 97-104

Epstein, M. and Cho, D. H. (1976): Melting Heat Transfer in Steady Laminar Flow over a Flat Plate, Journal of Heat Transfer, Vol. 98, pp. 531-533. http://dx.doi.org/10.1115/1.3450595

Gorla, R. S. R. and Sidawi, I. (1994): Free Convection on a Vertical Stretching Surface with Suction and Blowing, Applied Scientific Research, Vol. 52, pp. 247-257. http://dx.doi.org/10.1007/BF00853952

Huang, C. L. and Shih, Y. P. (1975): Perturbation Solution for Planar Solidification of a Saturated Liquid with Convection at the Wall, International Journal of Heat and Mass Transfer, Vol. 18, pp. 1481-1483. http://dx.doi.org/10.1016/0017-9310(75)90263-X

Ishak, A. (2010): Similarity Solutions for Flow and Heat Transfer over a Permeable Surface with Convective Boundary Condition, Applied Mathematics and Computation, Vol. 217, pp. 837-842. http://dx.doi.org/10.1016/j.amc.2010.06.026

Ishak, A., Nazar, R., Bachok, N. and Pop, I. (2010): Melting Heat Transfer in Steady Laminar Flow over a Moving Surface, Heat and Mass Transfer, Vol. 46, pp. 463-468. http://dx.doi.org/10.1007/s00231-010-0592-8

Ishak, A., Nazar, R. and Pop, I. (2008): Uniform Suction/Blowing Effect on Flow and Heat Transfer due to a Stretching Cylinder, Applied Mathematical Modeling, Vol. 32, pp. 2059-2066. http://dx.doi.org/10.1016/j.apm.2007.06.036

Nield, D. A. and Kuznetsov, A. V. (2009a): The Cheng-Minkowycz Problem for Mixed Convective Boundary Layer Flow in a Porous Medium Saturated by a Nanofluid," International Journal of Heat and Mass Transfer, Vol. 52, pp. 5792-5795. http://dx.doi.org/10.1016/j.ijheatmasstransfer.2009.07.024

Nield, D. A. and Kuznetsov, A. V. (2009b): Thermal Instability in a Porous Medium Layer Saturated by a Nanofluid, International Journal of Heat and Mass Transfer, Vol. 52, pp. 5796-5801. http://dx.doi.org/10.1016/j.ijheatmasstransfer.2009.07.023

Pantokratoras, A. (2009): A Common Error Made in Investigation of Boundary Layer Flows, Applied Mathematical Modeling, Vol. 33, pp. 413-422. http://dx.doi.org/10.1016/j.apm.2007.11.009

Patel, H. E., Das, S. K., Sundararajan, T., Sreekumaran, A., George B. and Pradeep, T. (2003): Thermal Conductivities of Naked and Monolayer Protected Metal Nanoparticle Based Nanofluids: Manifestation of Anomalous Enhancement and Chemical Effects, Applied Physics Letters, Vol. 83, pp. 2931-2933. http://dx.doi.org/10.1063/1.1602578

Pedroso, R.I. and Domoto, G.A. (1973): Perturbation Solutions for Spherical Solidification of Saturated Liquids, Journal of Heat Transfer, Vol. 95, pp. 42-46. http://dx.doi.org/10.1115/1.3450002

Sakiadis, B. C. (1961): Boundary-layer behavior on a continuous solid surface: II-The boundary layer on a continuous flat surface, AIChE Journal, Vol. 7, pp. 221-225. http://dx.doi.org/10.1002/aic.690070211

Tsou, F. K., Sparrow, E. M. and Goldstein, R. J. (1967): Flow and Heat Transfer In The Boundary Layer in the Continuous Moving Surfaces, Int. J. Heat Mass Transfer, Vol. 10, pp. 219-235. http://dx.doi.org/10.1016/0017-9310(67)90100-7

Wang, C.Y. (1988): Fluid Flow Due to a Stretching Cylinder, Physics of Fluids, Vol. 31, pp. 466-468. http://dx.doi.org/10.1063/1.866827

You, S. M., Kim, J. H. and Kim, K. H., (2003): Effects of Nanoparticles on Critical Heat Flux of Water in Pool Boiling Heat Transfer, Applied Physics Letters, Vol. 83, pp. 3374-3376. http://dx.doi.org/10.1063/1.1619206 